\title{
Esophagectomy first: A shift in the treatment algorithm for regionally advanced cancer? Only with brains and brawn
}

\author{
Virginia R. Litle, MD
}

See related article on pages 538-47.

With elegant statistics, Zahoor and colleagues at the University of Pittsburgh, the hub of the minimally invasive approach for surgical resection, present in this issue of the Journal a propensity-matched outcome analysis comparing patients undergoing upfront minimally invasive esophagectomy (MIE) for esophageal adenocarcinoma with those treated with neoadjuvant therapy followed by MIE. They try to bring down the wall built on a number of studies but cemented by the Chemoradiotherapy for Oesophageal Cancer Followed by Surgery Study (CROSS) trial endorsing neoadjuvant chemoradiation for all regionally advanced cases. ${ }^{1}$ The hypothesis was that patients treated with upfront surgical resection, followed by adjuvant therapy for those with clinical stage IIB or greater disease, would have a comparable overall survival to those undergoing neoadjuvant therapy (chemotherapy alone or chemoradiation) followed by surgical resection. All the patients had adenocarcinoma, and all underwent MIE. The conclusions? Upfront MIE (1) did not negatively affect overall survival, (2) allowed accurate pathologic staging, and (3) allowed downstaging so that $10 \%$ of patients did not need adjuvant therapy.

The results are compelling ... for surgeons who choose the minimally invasive approach. Zahoor and colleagues are not arguing any other way. That is their audience. Can they sway the advocates of open approaches to a less invasive procedure? The argument for many clinicians to offer the patient neoadjuvant therapy is that many patients will not tolerate adjuvant therapy if indicated after resection. Although it has not been reported specifically for MIE, allow me to extrapolate from the video-assisted thoracoscopic lobectomy literature ${ }^{2}$ and recent quality-of-life reports comparing MIE and open approaches. ${ }^{3}$ A minimally invasive approach to treatment of esophageal cancer may allow more patients to recover and feel prepared to receive additional therapy. Thus only those who are most

From the Division of Thoracic Surgery, Boston University, Boston, Mass.

Disclosures: Author has nothing to disclose with regard to commercial support.

Received for publication Oct 27, 2014; accepted for publication Oct 28, 2014; available ahead of print Nov 25, 2014

Address for reprints: Virginia R. Litle, MD, Division of Thoracic Surgery, Boston University, Robinson, B-402 88 E Newton St, Boston, MA 02118 (E-mail: virginia.litle@bmc.org).

J Thorac Cardiovasc Surg 2015;149:412-3

$0022-5223 / \$ 36.00$

Copyright (c) 2015 by The American Association for Thoracic Surgery

http://dx.doi.org/10.1016/j.jtcvs.2014.10.117 likely to benefit from adjuvant therapy would receive it, and they would feel physically strong enough to do so. The randomized, prospective Traditional Invasive Versus Minimally Invasive Esophagectomy (TIME) trial may lend stronger support for a minimally invasive approach improving quality of life. ${ }^{4}$

The current treatment algorithm of neoadjuvant therapy for most patients can change, but only with brains and brawn. Ultimately, we need brains; we need to get smarter about staging. The paradigm for the treatment of superficial cancers has shifted from esophagectomy to endoscopic mucosal resection. We need a smart modality to stage the disease in these patients so that we can extend our endoscopic mucosal resection applications more comfortably to certain submucosal lesions. Similarly, we need smarter technology to triage patients with clinically regionally advanced disease to neoadjuvant therapy. The literature to date is primarily directed at prognostic and predictive markers and less so at identification of nodal involvement. A report of a 4-gene signature from the Oesophageal Cancer Clinical and Molecular Stratification (OCCAMS) Study Group correlated with survival in node-positive patients and was an independent prognostic factor beyond TNM staging alone. ${ }^{5}$ Pretreatment gene expression profiles can predict the response to chemotherapy or chemoradiation therapy. ${ }^{6-8}$ Pathology and sophisticated amplification and hybridization techniques intersect to identify correlations between genomic aberrations and survival. ${ }^{9}$ Applying these techniques to primary tumors may allow stratification of patients with early stage disease to receive induction therapy. Gene signature profiling should be used to classify tumors not only as bad actors but also as node positive before nodes are even bisected and stained. Introduction of molecular staging into the current TNM stage would allow stratification to induction, adjuvant, or no therapy. Our energy should be directed at improving esophageal biomarkers for prognostic and therapeutic management. We look forward to advances in this area so that we may optimize clinical staging and targeted treatment to improve patient survival.

But until the brains have provided a tangible integrated genetic profiling, there's the brawn. The surgical corporation needs to be more technically proficient and able to do the MIE. In the Society of Thoracic Surgeons database, only about $25 \%$ of esophagectomies are approached minimally invasively. ${ }^{10}$ MIE is a long, technically challenging procedure with a steep learning curve, but are we doing a disservice to our patients by not offering an approach that could allow accurate staging for appropriate selection of 
adjuvant therapy and an approach that provides both less pulmonary morbidity compared with other transthoracic approaches and a better quality of life? Get smart, and do what's best for your esophageal cancer patients.

\section{References}

1. van Hagen P, Hulshof MC, van Lanschot JJ, Steyerberg EW, van Berge Henegouwen MI, Wijnhoven BP, et al. Preoperative chemoradiotherapy for esophageal or junctional cancer. N Engl J Med. 2012;366:2074-84.

2. Nicastri DG, Wisnivesky JP, Litle VR, Yun J, Chin C, Dembitzer FR, et al. Thoracoscopic lobectomy: report on safety, discharge independence, pain, and chemotherapy tolerance. J Thorac Cardiovasc Surg. 2012;135: 642-7.

3. Parameswaran R, Titcomb DR, Blencowe NS, Berrisford RG, Wajed SA, Streets CG, et al. Assessment and comparison of recovery after open and minimally invasive esophagectomy for cancer: an exploratory study in two centers. Ann Surg Oncol. 2013;20:1970-7.

4. Biere SS, Maas KW, Bonavina L, Garcia JR, van Berge Henegouwen MI, Rosman C, et al. Traditional invasive vs. minimally invasive esophagectomy: a multi-center, randomized trial (TIME-trial). BMC Surg. 2011;11:2.
5. Peters CJ, Rees JRE, Hardwick RH, Hardwick JS, Vowler SL, Ong CA, et al. A 4-gene signature predicts survival of patients with resected adenocarcinoma of the esophagus, junction, and gastric cardia. Gastroenterology. 2010;139: 1995-2004.e15.

6. Duong C, Greenawalt DM, Kowalczyk A, Ciavarella ML, Raskutti G, Murray WK, et al. Pretreatment gene expression profiles can be used to predict response to neoadjuvant chemoradiotherapy in esophageal cancer. Ann Surg Oncol. 2007; 14:3602-9.

7. Luthra R, Wu TT, Luthra MG, Izzo J, Lopez-Alvarez E, Zhang L, et al. Gene expression profiling of localized esophageal carcinomas: Association with pathologic response to preoperative chemoradiation. J Clin Oncol. 2006; 24:259-67.

8. Izzo JG, Malhotra U, Wu TT, Ensor J, Luthra R, Lee JH, et al. Association of activated transcription factor nuclear factor $\kappa \mathrm{b}$ with chemoradiation resistance and poor outcome in esophageal carcinoma. J Clin Oncol. 2006;24: 748-54.

9. Pasello G, Agata S, Bonaldi L, Corradin A, Montagna M, Zamarchi R, et al. DNA copy number alterations correlate with survival of esophageal adenocarcinoma patients. Mod Pathol. 2009;22:58-65.

10. Data analyses of the Society of Thoracic Surgeons General Surgery Database. Sixteenth report for period ending 12/31/2012. Chicago: The Society of Thoracic Surgeons; 2013. 